\title{
OR-12
}

\section{BLENDS OF POLY-3-HYDROXYBUTYRATE AND POLY-E-CAPROLACTONE: MORPHOLOGY, PROPERTIES AND BIOCOMPATIBILITY}

\author{
A. ‥ Boyandin, ${ }^{1,2}$ A. A. Sukhanova, ${ }^{1}$ E. D. Nikolaeva, ${ }^{3}$ A. G. Sukovatyi ${ }^{2}$ \\ ${ }^{1}$ Reshetnev Siberian State University of Science and Technology, \\ 31 Krasnoyarsky Rabochy Ave., Krasnoyarsk, 660037, Russia. \\ ${ }^{2}$ Institute of Biophysics of the Siberian Branch of the Russian Academy of Sciences, Federal Research \\ Center "Krasnoyarsk Science Center of the Siberian Branch of the Russian Academy of Sciences", 50, \\ build. 50, Akademgorodok, Krasnoyarsk 660036, Russia. \\ ${ }^{3}$ International Scientific Centre for Studying Extreme States of an Organism, Federal Research Center \\ "Krasnoyarsk Science Center of the Siberian Branch of the Russian Academy of Sciences”, 50, \\ build.12/2, Akademgorodok, Krasnoyarsk 660036, Russia. \\ E-mail: araneus@mail.ru
}

\begin{abstract}
The use of biocompatible and biodegradable polymers is essential for modern biomedicine. One of the approaches to improving the mechanical properties of pure polymers is to obtain mixtures based on them. A series of films was obtained from blends of poly-3-hydroxybutyrate (PHB) and poly- $\varepsilon$-caprolactone (PCL). The structure, physical, mechanical and biological properties of the films were investigated, depending on the ratio of the components. The microscopic structure of films was determined by the main component of the blend: the films were porous with a predominance of PHB and relatively smooth with a predominance of PCL. The highest values of elongation at break (229-269\%), as well as the local maximum values of tensile strength (14-15 MPa) are noted for mixtures with a PHB content of 5-25\%. At a PHB content of $25 \%$ and $75 \%$, local maxima of Young's modulus are observed (507 and $655 \mathrm{MPa}$, respectively). When the ratio of the components in the mixture was equal (50:50 by weight), the films were heterogeneous and had the lowest total indicators of mechanical strength (ultimate strength and elongation at break were $3 \mathrm{MPa}$ and $15.5 \%$, respectively). A study of the biocompatibility of mixed films in a culture of NIH 3T3 mouse fibroblasts based on the results of DAPI staining and determination of the number of adhered cells in the MTT test showed the absence of cytotoxic action, as well as high adhesion and cell proliferation, in some cases exceeding the data for films from pure PHB and PCL. This demonstrates the suitability of PHB-PCL mixtures for the production of cell carriers for tissue engineering and other reconstructive technologies.
\end{abstract}

Table 1. Properties of films from PHB and PCL blends

\begin{tabular}{|c|c|c|c|c|}
\hline $\begin{array}{c}\text { PHB/PCL, } \\
\%\end{array}$ & $\begin{array}{c}\text { Tensile } \\
\text { strength, MPa }\end{array}$ & $\begin{array}{c}\text { Young's } \\
\text { modulus, MPa }\end{array}$ & $\begin{array}{c}\text { Elongation at } \\
\text { break, \% }\end{array}$ & $\begin{array}{c}\text { MTT, 7 days, } \\
\text { cells } \times 10^{5} / \mathrm{cm}^{2}\end{array}$ \\
\hline $100 / 0$ & $20.1 \pm 3.6$ & $3147 \pm 67$ & $1.48 \pm 0.07$ & $2.18 \pm 0.47$ \\
\hline $95 / 5$ & $29.6 \pm 5.2$ & $2690 \pm 196$ & $2.02 \pm 0.07$ & $3.37 \pm 0.64$ \\
\hline $90 / 10$ & $22.3 \pm 4.4$ & $1815 \pm 199$ & $4.35 \pm 0.46$ & $2.91 \pm 0.29$ \\
\hline $75 / 25$ & $8.3 \pm 1.3$ & $655 \pm 63$ & $35.0 \pm 2.2$ & $3.40 \pm 0.35$ \\
\hline $50 / 50$ & $3.1 \pm 0.5$ & $194 \pm 22$ & $15.5 \pm 1.2$ & $3.52 \pm 0.89$ \\
\hline $25 / 75$ & $14.8 \pm 2.1$ & $507 \pm 33$ & $229.2 \pm 9.6$ & $4.14 \pm 0.71$ \\
\hline $10 / 90$ & $14.8 \pm 1.8$ & $361 \pm 23$ & $255.1 \pm 14.3$ & $2.32 \pm 0.24$ \\
\hline $5 / 95$ & $13.9 \pm 2.3$ & $234 \pm 19$ & $268.8 \pm 18.5$ & $2.52 \pm 0.44$ \\
\hline $0 / 100$ & $9.4 \pm 1.1$ & $238 \pm 14$ & $129.9 \pm 22.4$ & $2.93 \pm 0.42$ \\
\hline
\end{tabular}

This work was carried within the state assignment of the Ministry of Science and Higher Education of the Russian Federation, project No. FEFE-2020-0015. 